\title{
Effect of Geometrical Parameters On Sensitivity And Volume Of Dual Octal Ring
}

\author{
Varsha Anil Kamble, Student \\ D.K.T.E.Society's Textile And Engineering Institute, \\ Ichalkaranji, India. \\ Vijay A. Kamble, Asst.Professor \\ Mechanical Engineering, Dktes Textile and \\ engineering Institute Ichalkaranji, India.
}

\begin{abstract}
Force transducer is one of the load cell which is used to measure force or weight, pressure etc. various types of transducers are manufacturing for various applications. But most of strain gauge type of transducer is used. In current research, optimization of octagonal type of force transducer design is carried out by maximizing sensitivity and minimizing the volume. Force transducer is analyze with the help of finite element method and find the critical parameters, its effect also as sensitivity and volume. Response surface methodology is used for experimental set up. For performance of all parameters analysis of variance is carried out and multi-objective optimization is also performed.
\end{abstract}

KEYWORDS: Force transducer, sensitivity, volume, finite element method, response surface method, optimization, analysis of variance.

\section{INTRODUCTION}

Force transducer have been playing a vital role in applications like testing of material testing machines, electronic weighing balance, weighing of aircrafts, thrust measurement of jet or rocket engines, monitoring components of cutting forces in different machining processes etc, thus insisting accurate and precise measurement of force[Harish Kumar, 2011]. Among the complete range of sensors and transducers used in automotive, research, consumer and industrial applications, load cells stand out as one of the most significant transducers. Basically, these transducers used to calculate deformations produced by force [Hernandez et.al, 2006]. The force transducer contain a spring element . This design is most critical mechanical component in force transducer. When any force is applied on the force transducer, these spring element shows variation with respect to applied force. These variations subjected to tensile or compressive force. Double octagonal type design uses strain gauges to examine the stress sensing in sensing element. So, for current research 'double octagonal' type force transducer is used for shape optimization. Shape optimization is a process of changing the physical dimensions of a structural part to increase sensitivity and reduce the volume. Multi-objective optimization of sensitivity and volume parameters were investigated by response surface methodology. 


\section{DESIGN OF EXPERIMENT}

The material used for this experiment is Aluminium Alloy 6061 T6, because its wear resistance and toughness are high and also its property are as follows :-

1. Young's Modulus $=0.7 * 10^{5} \mathrm{MPa}$

2. Poisson's ratio $=0.33$

3. Material density $=2770 \mathrm{Kg} / \mathrm{m}^{3}$

Constraints for this experiment are as follows-

1. Force transducer is fixed to rigid support.

2. Uniformly distributed load is acting on top surface of force transducer.

3. At the location of strain gauges values of strains are measured.

4. Maximum strain induced is less than $1500 \mu$ strain.

'Octagonal plate' type structure is selected for this experiment. In this design 3 critical parameters are considers, Upper thickness 'a ' $(6 \mathrm{~mm})$, Lower thickness 'b ' $(8 \mathrm{~mm})$, Height 'c ' $(100 \mathrm{~mm})$ shown in fig.1 As strain gauges are mounted on faces of force transducer. The parameters and corresponding level for octagonal plate is shown in table 1. 


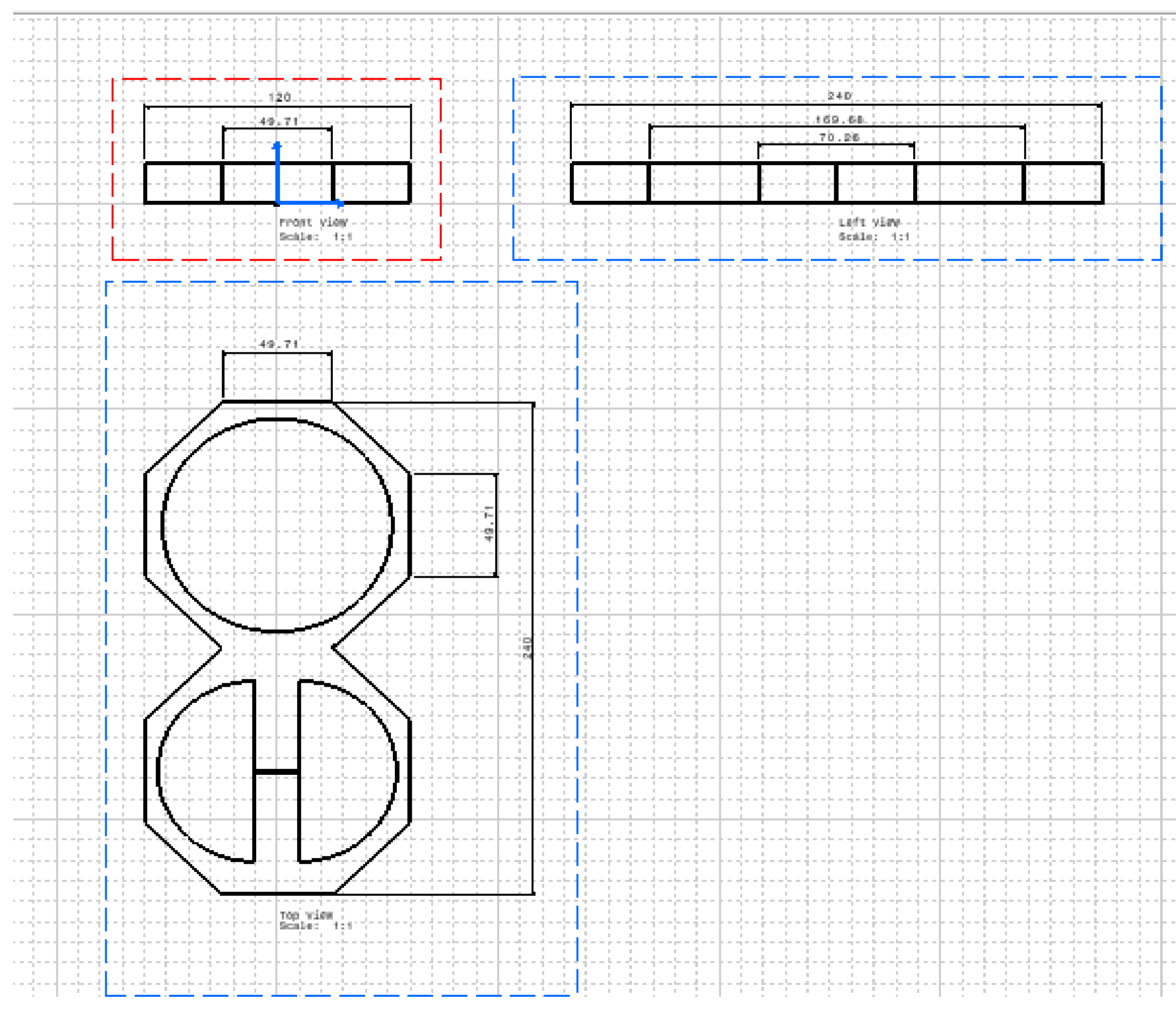

Fig.1 Conceptual design of octagonal plate with its critical dimensional parameters

Table 1 Level of critical parameters

\begin{tabular}{|l|l|l|l|l|l|}
\hline Sr. No. & Parameters & Units & Level 1 & Level 2 & Level 3 \\
\hline 1 & $\mathrm{a}$ & $\mathrm{Mm}$ & 6 & 8 & 10 \\
\hline 2 & $\mathrm{~b}$ & $\mathrm{Mm}$ & 6 & 8 & 10 \\
\hline 3 & $\mathrm{c}$ & $\mathrm{Mm}$ & 90 & 100 & 110 \\
\hline
\end{tabular}

By using response Surface Methodology our experiment is carried out. There are 9 experiments which consist of 3 parameters which each having 3 levels. 
Table 2 : Experimental observations for sensitivity and volume

\begin{tabular}{|l|l|l|l|l|l|}
\hline \multirow{2}{*}{ Trial No. } & \multicolumn{3}{|l|}{ Process Parameters } & \multicolumn{2}{l|}{ Response Variable } \\
\cline { 2 - 6 } & $\begin{array}{l}\text { Upper } \\
\text { thickness [A] } \\
\mathbf{m m}\end{array}$ & $\begin{array}{l}\text { Lower } \\
\text { thickness [B] } \\
\mathbf{M m}\end{array}$ & $\begin{array}{l}\text { Height [C] } \\
\mathbf{M m}\end{array}$ & $\begin{array}{l}\text { Volume } \\
\mathbf{m m}^{\mathbf{3}}\end{array}$ & $\begin{array}{l}\text { Sensitivity } \\
\boldsymbol{\mu s t r a i n} / \mathbf{N}\end{array}$ \\
\hline 1 & 6 & 6 & 90 & 107.9 & 0.96475 \\
\hline 2 & 6 & 8 & 100 & 133.6 & 0.93581 \\
\hline 3 & 6 & 10 & 110 & 161.6 & 0.11452 \\
\hline 4 & 8 & 6 & 100 & 132 & 0.51230 \\
\hline 5 & 8 & 8 & 110 & 160.5 & 0.59162 \\
\hline 6 & 8 & 10 & 90 & 134.4 & 0.4746 \\
\hline 7 & 10 & 6 & 110 & 158.4 & 0.46699 \\
\hline 8 & 10 & 8 & 90 & 132.8 & 0.36083 \\
\hline 9 & 10 & 10 & 100 & 161.8 & 0.44929 \\
\hline
\end{tabular}

The above 9 trials were run to find out the effect of parameters. In response surface method volume and sensitivity are response variable. And also upper thickness, lower thickness and height are selected parameters. The goal for this experimental study is to achieve volume is minimum and at same experiment sensitivity is maximum.

\section{FINITE ELEMENT METHOD}

Finite element method is used to solve critical engineering problems. When experimental model is very difficult to evaluate and having no theoretical solution then that this time we use the finite element method. In current research finite element analysis is used by using ansys 16.2 software. Following process is carried out in this software shown in fig. 2

SPECIFY THE NATURE OF FORCE (STATIC)

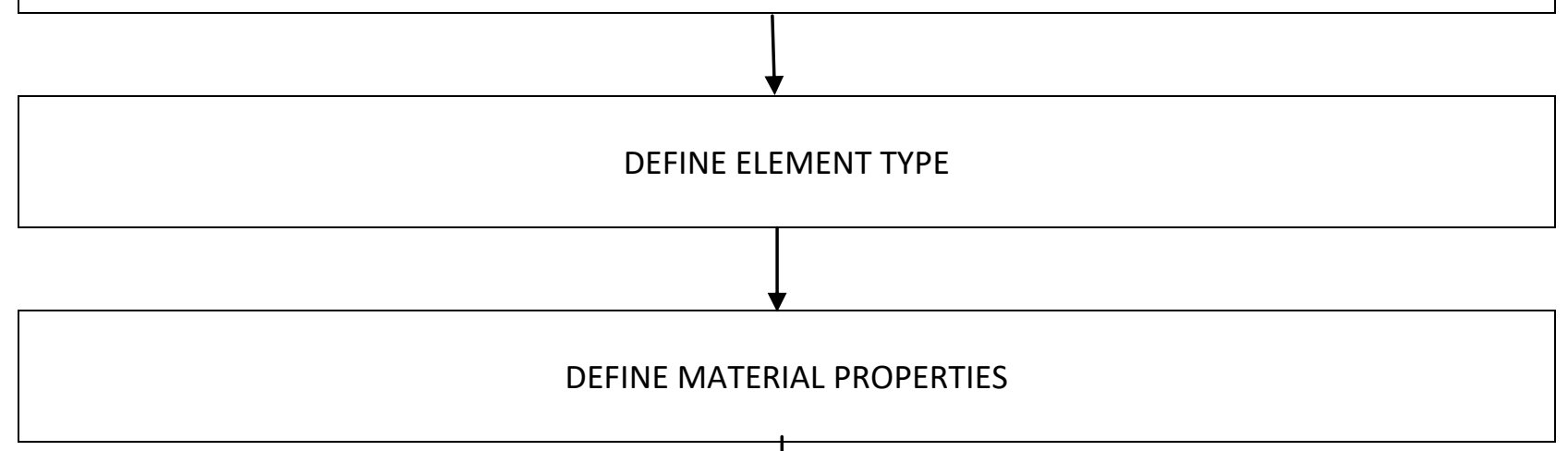




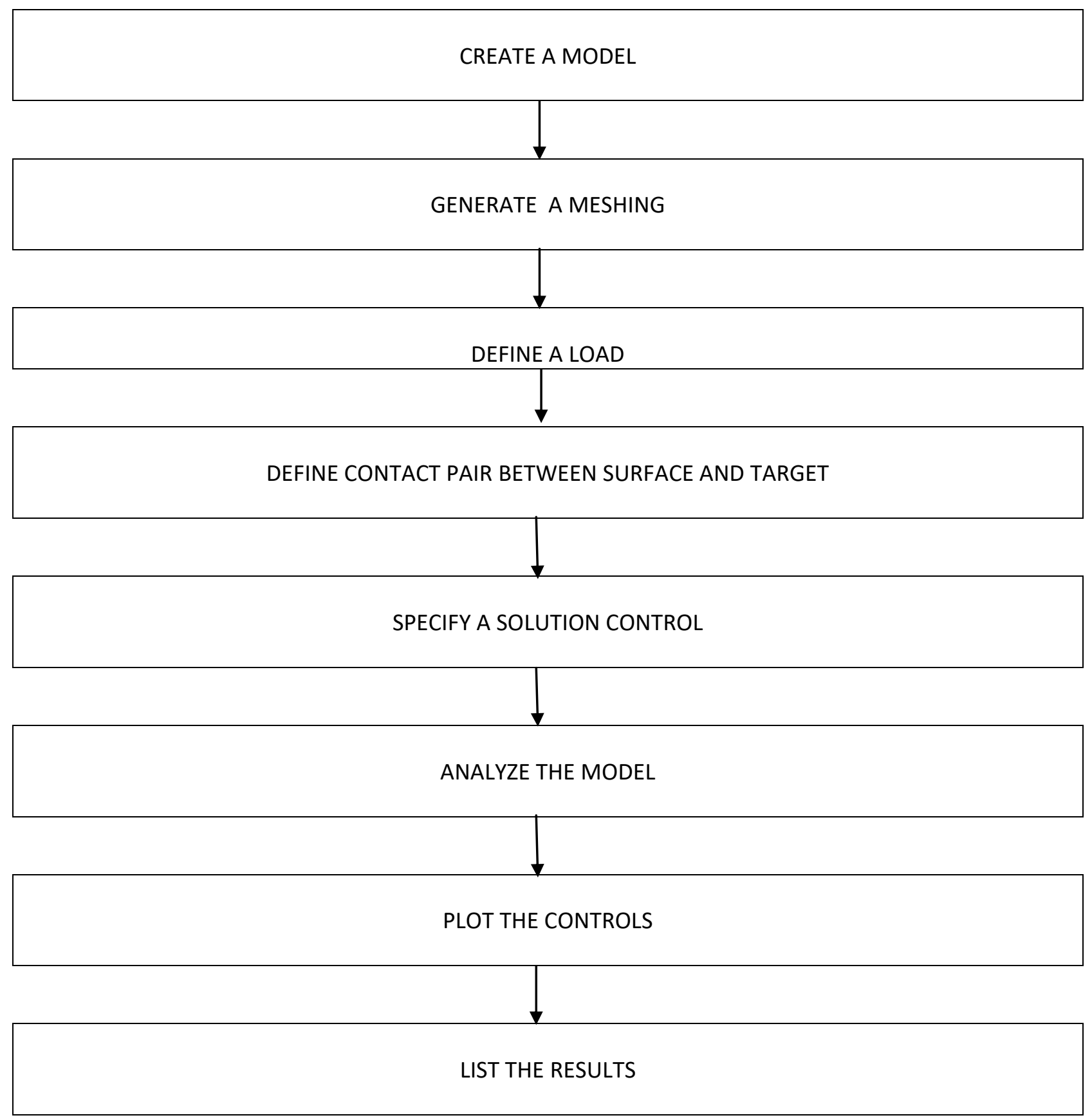

Fig.2: Process in FEM 


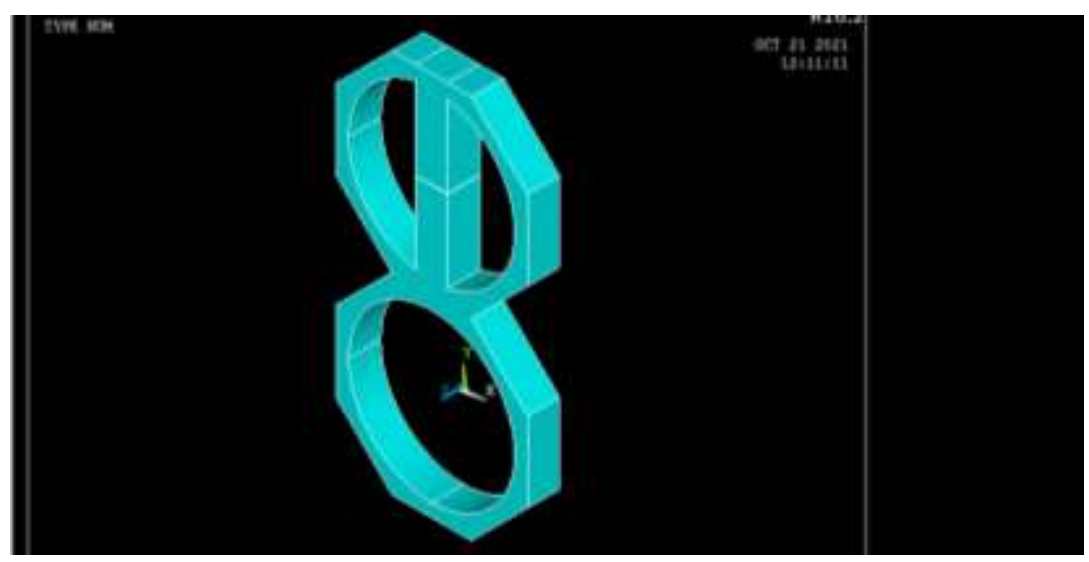

3D model

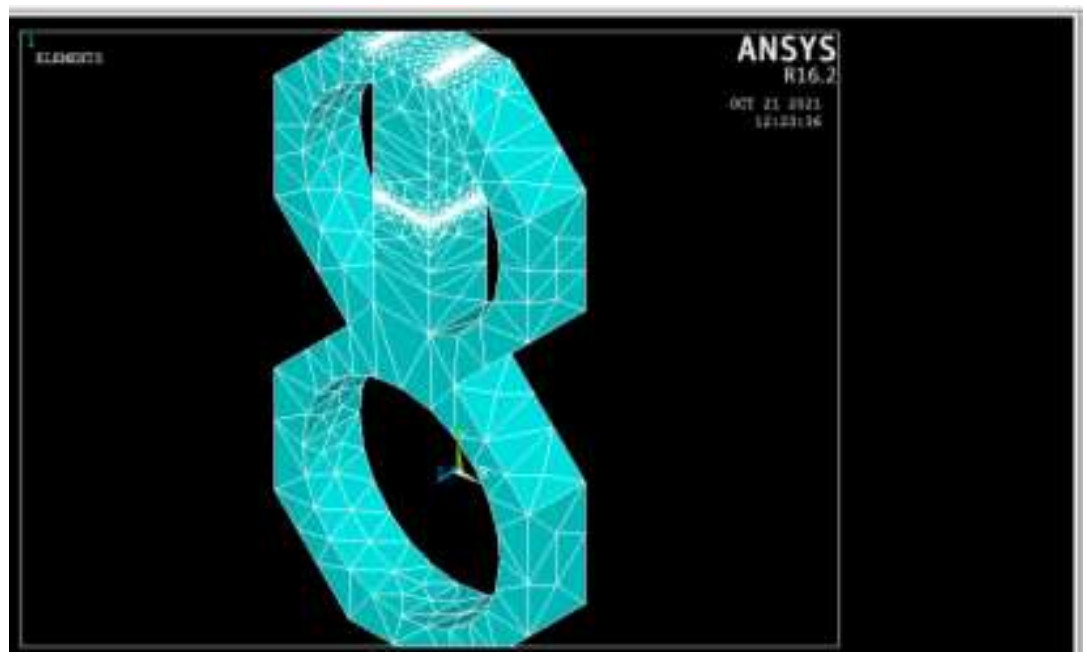

Meshed model

Fig.3: Steps in FEM

\section{RESPONSE SURFACE METHODOLOGY}

Response surface method is used to evaluate the functions describing the relationship among some influencing factors and the process results. Box and Wilson introduced RSM in 1951 and then Montgomery and Myers [Myerse.al, 2003] developed it. The most important purpose of RSM is to use a series of designed experiments to attain an optimal response. In many cases, a second-degree polynomial model is used in RSM. This model is only an approximation, but because of its flexibility it is widely used (Almirzaloo et.al, 2012). This model is expressed as,

$y=\beta_{0}+\sum_{i=1}^{k} \beta_{i} x_{i}+\sum_{i=1}^{k} \beta_{i j} x_{i} x_{j}^{2}+\sum_{i=1}^{k} \beta_{i j} x_{i} x_{j}+\varepsilon_{p}$

Where, $y$ is the response, $\beta 0, \beta \mathrm{i}, \beta \mathrm{ii}, \beta \mathrm{ij}$ are unknown constant coefficients and $\mathrm{xi}$ and $\mathrm{xj}$, denote the independent design variables, $\mathrm{k}$ is the number of the independent variables, and $\varepsilon$ is the statistical error. 
The coefficients of the model equation are obtained using regression methods. The Minitab software was used to analyze the data. Each of the variables considered in three levels that are shown in Table 3.

\section{MULTI-OBJECTIVE OPTIMIZATION}

The purpose of optimization is to find one or several acceptable solutions to the critical values of one or more of the objective functions. Optimization methods are important in practice, especially in engineering design, experimental test and trading decisions (Nagaile et.al, 2004). When a problem involves more than one objective function, finding process of the optimal response is called multiobjective optimization. Desirability function is one of the multi-objective optimization methods that is used in this study. To optimize by using desirability function, firstly the individual desirability degree for each response should be calculated. If the aim is to minimize a response, the individual desirability is calculated using Equation (2). Also, Equation (3) is used for maximizing the response.

$$
\begin{array}{r}
d_{i}=\left\{\begin{array}{lr}
0 & y_{i}>U_{i} \\
{\left[\frac{\left(U_{i}-y_{i}\right)}{\left(U_{i}-T_{i}\right)}\right]^{r_{i}}} & T_{i} \leq y_{i} \leq U_{i} \\
1 & y_{i}<T_{i}
\end{array}\right. \\
d_{i}=\left\{\begin{array}{lr}
0 & y_{i}<L_{i} \\
{\left[\frac{\left(y_{i}-L_{i}\right)}{\left(T_{i}-L_{i}\right)}\right]^{r_{i}}} & L_{i} \leq y_{i} \leq T_{i} \\
1 & y_{i}>T_{i}
\end{array}\right.
\end{array}
$$

In Equations (2) and (3), di is the individual desirability degree, yi represents the predicted value, $\mathrm{Ti}$ is the target value, Ui denotes the maximum acceptable value, $L i$ is the minimum acceptable value and $\mathrm{ri}$ represents the weight of desirability function for the ith response. In this research, response volume should be minimum, therefore Equation (2) is used and sensitivity should be maximum, therefore Equation (3) is used. After calculating the individual desirability degree for each function, in order to use them to combine all the answers and finding overall proper conditions, the composite desirability is obtained using Equation (4) in which $D$ is the composite desirability degree, wi represents the importance of ith response and $W$ is the overall weight.

$\mathrm{D}=(\Pi($ di wi $)) 1 / \mathrm{w}(4) \mathrm{D}=\left(\pi\left(d_{i} W_{i}\right)\right)^{1 / w}$

Since the ultimate goal of this research is to achieve the less volume and maximum sensitivity of load cell, the importance for both objective functions is considered one. Likewise the desirability function weight for each response is considered one. This is the default weight and is called linear desirability function [Camra et.al, 2014].

\section{RESULT AND DISCUSSION EFFECT OF PARAMETERS ON VOLUME}

Input parameters are upper thickness [a], lower thickness[b], and height[c] will be expressed in volume equation, 
Volume $=-4.200+0.09167[\mathrm{~A}]+0.8917[\mathrm{~B}]+0.2867[\mathrm{C}]+0.09583[\mathrm{~A}] *[\mathrm{~A}]+0.09583[\mathrm{~B}] *[\mathrm{~B}]$ $+0.007667[\mathrm{C}] *[\mathrm{C}]+0.3167[\mathrm{~A}] *[\mathrm{~B}]-0.000000[\mathrm{~A}] *[\mathrm{C}]$

By using Analysis Of Variance (ANOVA) technique, observe the performance of selected parameters and it is suitable to regression model. Result of given model of volume are represented in Table 3.The $P$ values less than 0.05 it is sign of selected parameters are effective. The terms linear, square and interactions are shows the highly effective in regression model

Table 3: ANOVA for Response Model of Volume

\begin{tabular}{|l|l|l|l|}
\hline Source & Degree of Freedom & Adj. Sum of Square & Adj. Mean Square \\
\hline Model & 8 & 2860.40 & 357.550 \\
\hline Linear & 3 & 2078.43 & 692.811 \\
\hline A & 1 & 415.0 & 415.002 \\
\hline B & 1 & 295.02 & 295.021 \\
\hline C & 1 & 993.72 & 993.72 \\
\hline Square & 3 & 1.3 & 0.434 \\
\hline A*A $^{*}$ B & 1 & 0.29 & 0.294 \\
\hline C*C $^{*}$-Way Interaction & 1 & 0.22 & 0.22 \\
\hline A*B & 1 & 0.88 & 0.882 \\
\hline A*C & 2 & 3.21 & 1.604 \\
\hline Error & 1 & 2.41 & 2.407 \\
\hline Total & 1 & 0 & 0 \\
\hline
\end{tabular}

Regression Equation

Volume $=-106.04+4.158[\mathrm{~A}]+4.958[\mathrm{~B}]+1.7567[\mathrm{C}]$

\begin{tabular}{|l|l|l|l|l|l|}
\hline Parameters & $\begin{array}{l}\text { Degree of } \\
\text { Freedom }\end{array}$ & $\begin{array}{l}\text { Adj. Sum of } \\
\text { Square }\end{array}$ & $\begin{array}{l}\text { Adj. Mean } \\
\text { Square }\end{array}$ & F- Value & P-Value \\
\hline Regression & 3 & 0.27074 & 0.09025 & 1.63 & 0.294 \\
\hline A & 1 & 0.08354 & 0.08354 & 1.51 & 0.273 \\
\hline B & 1 & 0.12779 & 0.12779 & 2.31 & 0.189 \\
\hline C & 1 & 0.05941 & 0.05941 & 1.08 & 0.347 \\
\hline Error & 5 & 0.27612 & 0.05522 & & \\
\hline Total & 8 & & & & \\
\hline
\end{tabular}

Figure 4 shows response surface of volume according to upper thickness [a] and lower thickness[b].In figure 5 response surface of volume according to lower thickness[b] and height $[c]$ is shown.

Figure 4and 5 shows that when upper thickness[a] and lower thickness[b] are increases then volume also increases. And in other hand selected parameters; Upper thickness[a], Lower thickness [b] and height are decreases therefore its result shows 


\section{Contour Plot of Volume vs Lower thickness [B] mm, Upper thickness [A]}
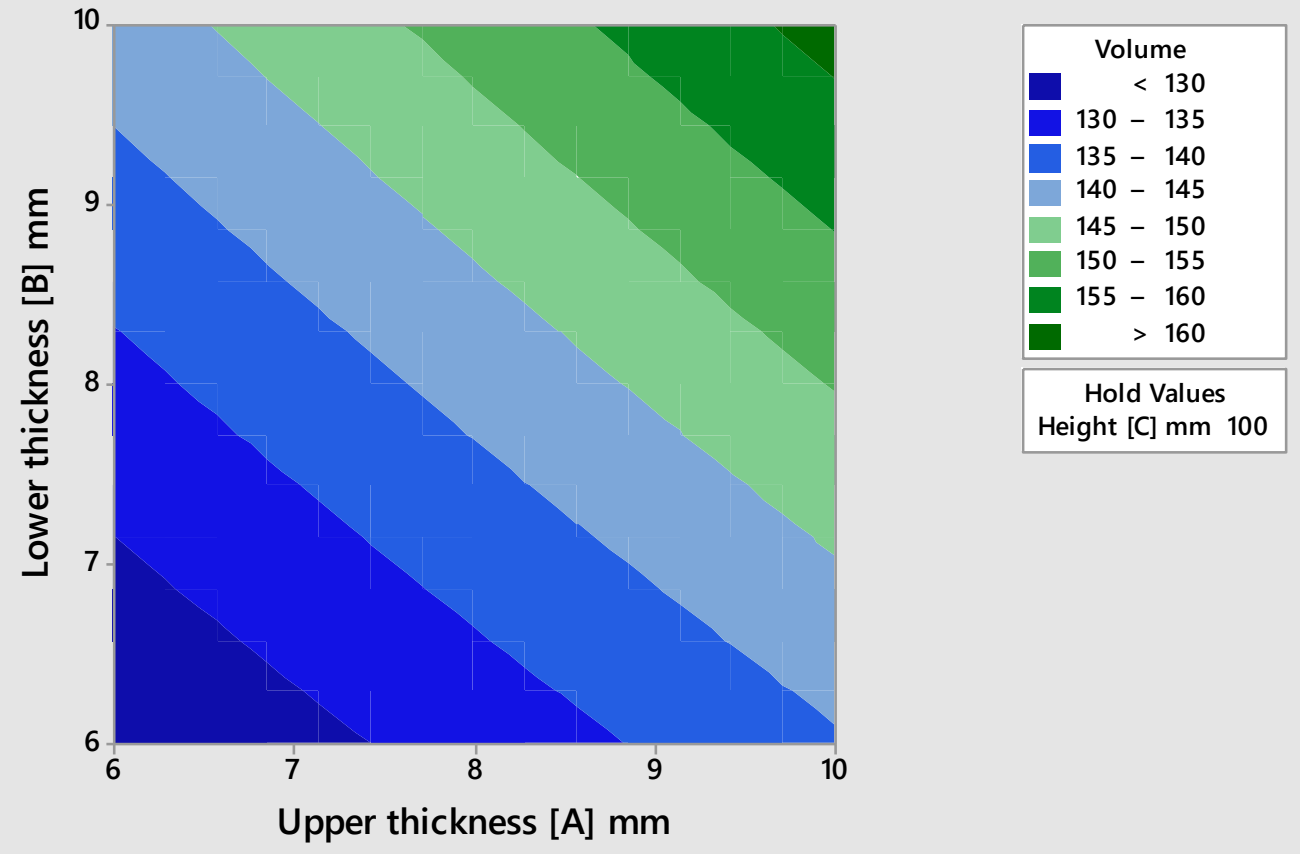

Fig.4: Response Surface of volume according to lower thickness (B) and upper thickness (A)

\section{Contour Plot of Volume vs Height $[\mathrm{C}] \mathrm{mm}$, Lower thickness [B] $\mathrm{mm}$}
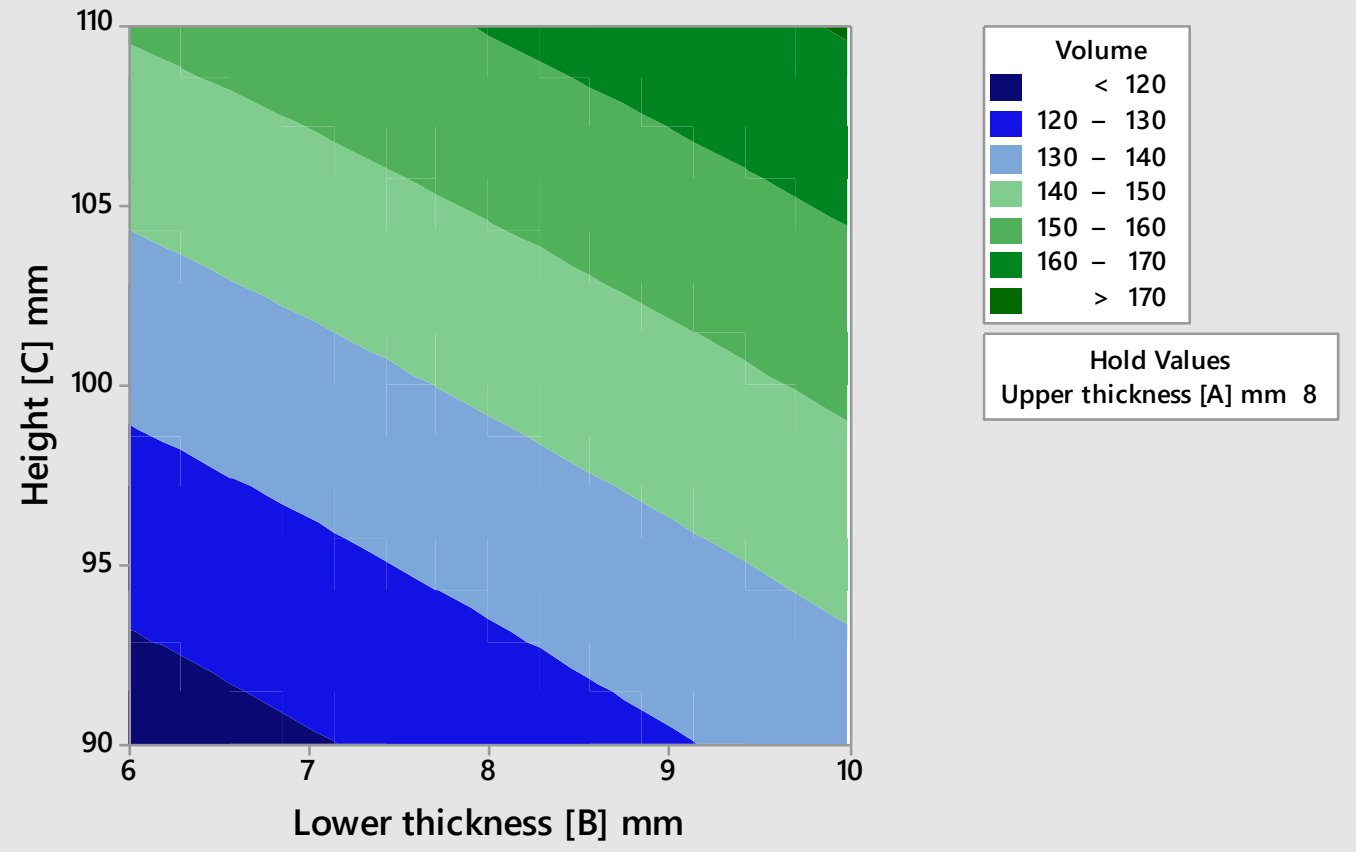

Fig.4: Response Surface of volume according to lower thickness (B) and height (C) 


\section{Contour Plot of Volume vs Height $[\mathrm{C}] \mathrm{mm}$, Upper thickness $[\mathrm{A}] \mathrm{mm}$}
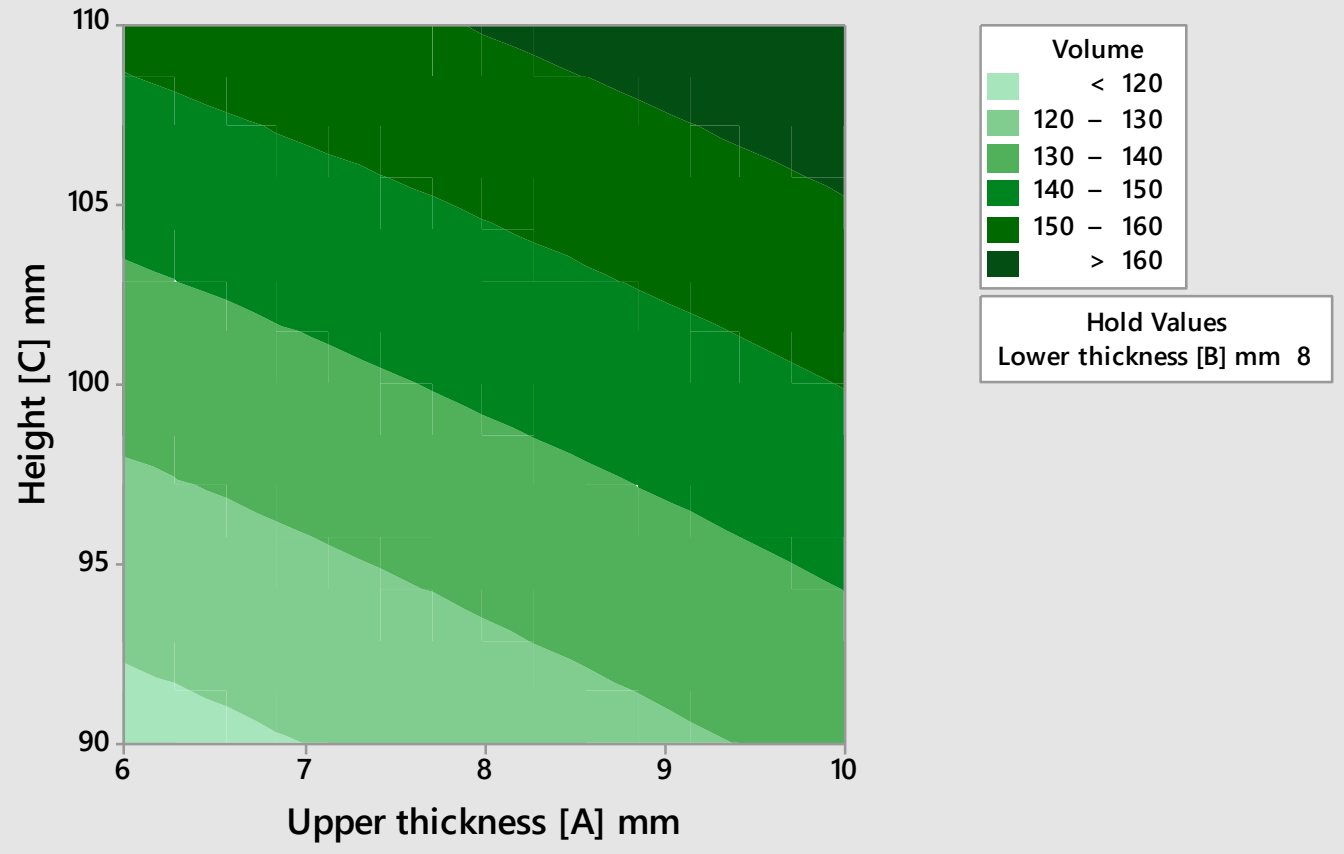

Fig.6: Response Surface of volume according to height (C) and upper thickness (A)

According to figures 4-6, it is clear that with increasing parameters Upper thickness (A), Lower thickness (B) and Height (C) volume is increased.

\section{EFFECT OF PROCESS PARAMETERS ON SENSITIVITY}

Input parameters are upper thickness [a], lower thickness[b], and height[c] will be expressed in sensitivity equation,

sensitivity strain $N=-2.362-1.678[A]+1.078[B]+0.1241[C]+0.004381[A]^{*}[A]-0.07141[B]^{*}[B]-$ $0.001255[C] *[C]+0.008188[A] *[B]+0.01483[A] *[C]$

By using Analysis Of Variance (ANOVA) technique, observe the performance of selected parameters and it is suitable to regression model. Result of given model of volume are represented in Table 3.The $P$ values less than 0.05 it is sign of selected parameters are effective. The terms linear, square and interactions are shows the highly effective in regression model 
Table 4: ANOVA for Response Surface Model of Sensitivity

\begin{tabular}{|l|l|l|l|}
\hline Source & Degree of Freedom & Adj.SS & Adj.MS \\
\hline Model & 8 & 0.546855 & 0.068357 \\
\hline Linear & 3 & 0.105356 & 0.035119 \\
\hline A & 1 & 0.083537 & 0.083537 \\
\hline B & 1 & 0.000017 & 0.000017 \\
\hline C & 1 & 0.020733 & 0.020733 \\
\hline Square & 3 & 0.135294 & 0.045098 \\
\hline$A^{*} A$ & 1 & 0.000614 & 0.000614 \\
\hline$B^{*} B$ & 1 & 0.122382 & 0.122382 \\
\hline$C^{*} C$ & 1 & 0.023640 & 0.023640 \\
\hline $2-$ Way Interaction & 2 & 0.197497 & 0.098749 \\
\hline A*B & 1 & 0.001609 & 0.001609 \\
\hline A*C & 1 & 0.131943 & 0.131943 \\
\hline Error & 0 & & \\
\hline Total & 8 & 0.546855 & \\
\hline
\end{tabular}

Regression Equation

sensitivity strain $N=2.59-0.0590[A]-0.0730[B]-0.00995[C]$

\begin{tabular}{|l|l|l|l|l|l|}
\hline Parameters & $\begin{array}{l}\text { Degree of } \\
\text { Freedom }\end{array}$ & $\begin{array}{l}\text { Adj. Sum of } \\
\text { Square }\end{array}$ & $\begin{array}{l}\text { Adj. Mean } \\
\text { Square }\end{array}$ & F-Value & P-Value \\
\hline Regression & 3 & 0.27074 & 0.09025 & 1.63 & 0.294 \\
\hline A & 1 & 0.08354 & 0.08354 & 1.51 & 0.273 \\
\hline B & 1 & 0.12779 & 0.12779 & 2.31 & 0.189 \\
\hline C & 1 & 0.05941 & 0.05941 & 1.08 & 0.347 \\
\hline Error & 5 & 0.27612 & 0.05522 & & \\
\hline Total & 8 & & & & \\
\hline
\end{tabular}

Figure 7 shows response surface of sensitivity according to upper thickness [a] and lower thickness[b].In figure 8 response surface of sensitivity according to lower thickness[b] and height $[c]$ is shown.

Figure 7 and 8 shows that when upper thickness[a] and lower thickness[b] are increases then sensitivity also increases. And in other hand selected parameters; Upper thickness[a], Lower thickness [b] and height are decreases therefore its result shows. 


\section{Contour Plot of sensitivity vs Lower thickness [B] mm, Upper thicknes}

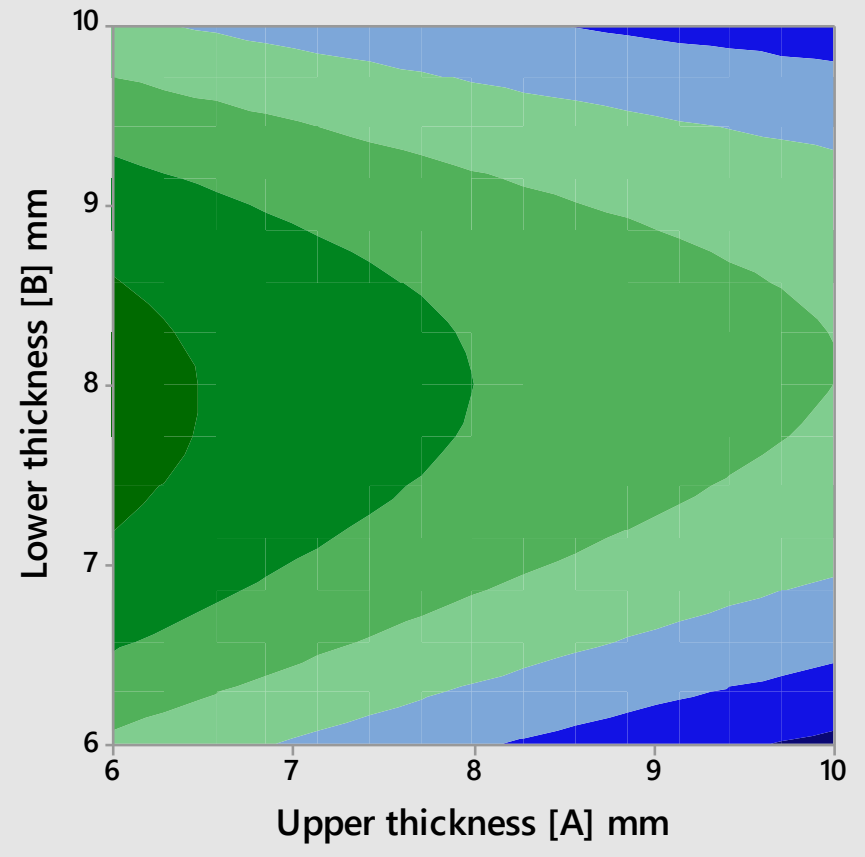

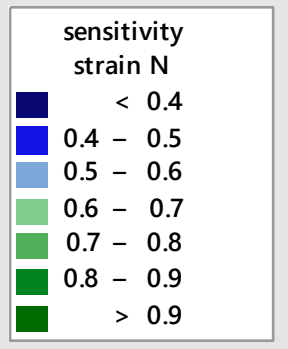

Hold Values Height $[\mathrm{C}] \mathrm{mm} 100$

Fig.7: shows response surface of volume according to upper thickness [a] and lower thickness[b].

Contour Plot of sensitivity vs Height $[C] \mathrm{mm}$, Lower thickness [B] $\mathrm{mm}$

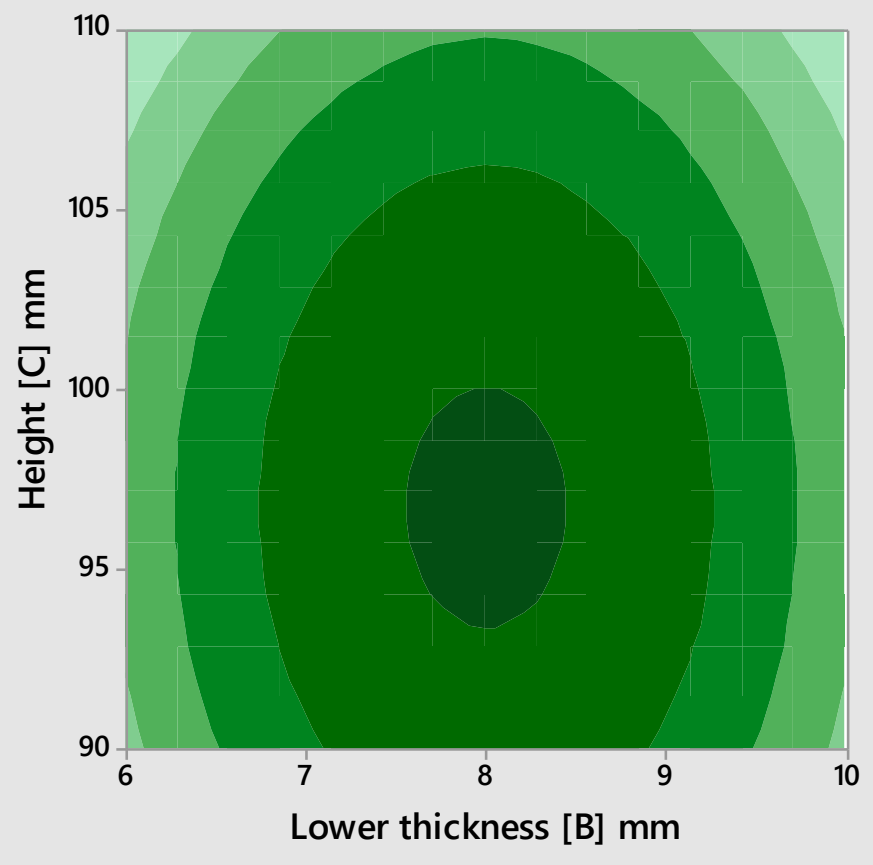

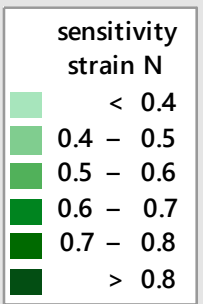

Hold Values

Upper thickness $[\mathrm{A}] \mathrm{mm} 8$

Fig.8: shows response surface of volume according to lower thickness [a] and height[C]. 


\section{Contour Plot of sensitivity vs Height $[C] \mathrm{mm}$, Upper thickness $[A] \mathrm{mm}$}
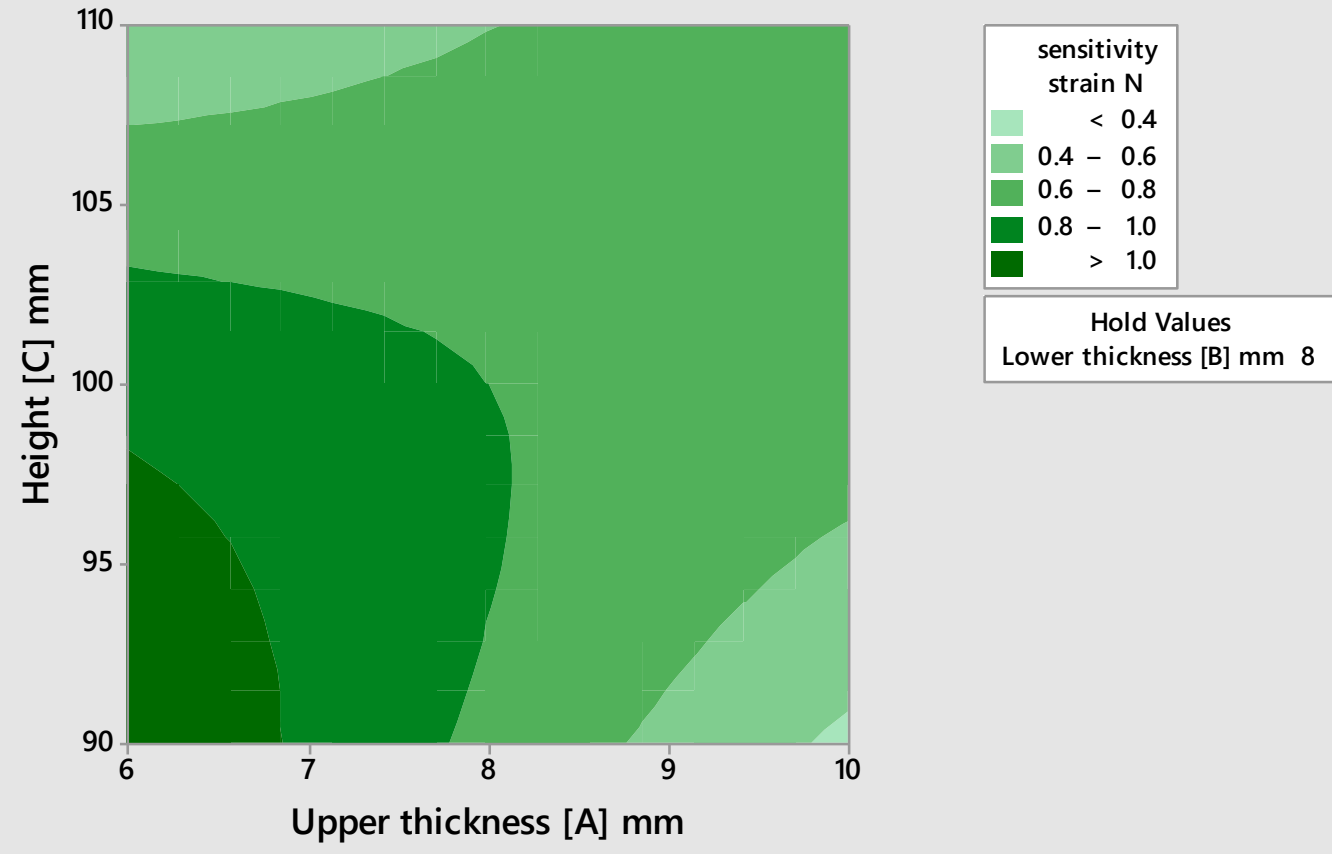

Fig.9: response surface of volume according to upper thickness[A] and height[c]

\section{OPTIMIZATION PROCESS}

In order to use the desirability function, an area should be specified to obtain optimum point. The volume should be minimum and sensitivity should be maximum. For this issue, first the target and the upper bound should be determined (Alimirzaloo, 2016). By using desirability function, achieve the goal and to obtain the optimum point. For the response volume, the target value is selected 107.9. This value is considered from run number 1 of Table 2 in which the lowest volume for force transducer is obtained. Also the upper bound is selected 161.8 which is considered from run number 9 of table 2 . For the response sensitivity the target value selected is 0.96475 which is maximum selected from run number 5 of table 1 . For the response sensitivity the target value selected is 0.11452 which is minimum selected from run number 3 of table 2. The optimization results using the mentioned information are shown in Figure 10. According to this figure, the composite desirability of the obtained point is 0.9996 . Table 5 shows the optimal point values. 


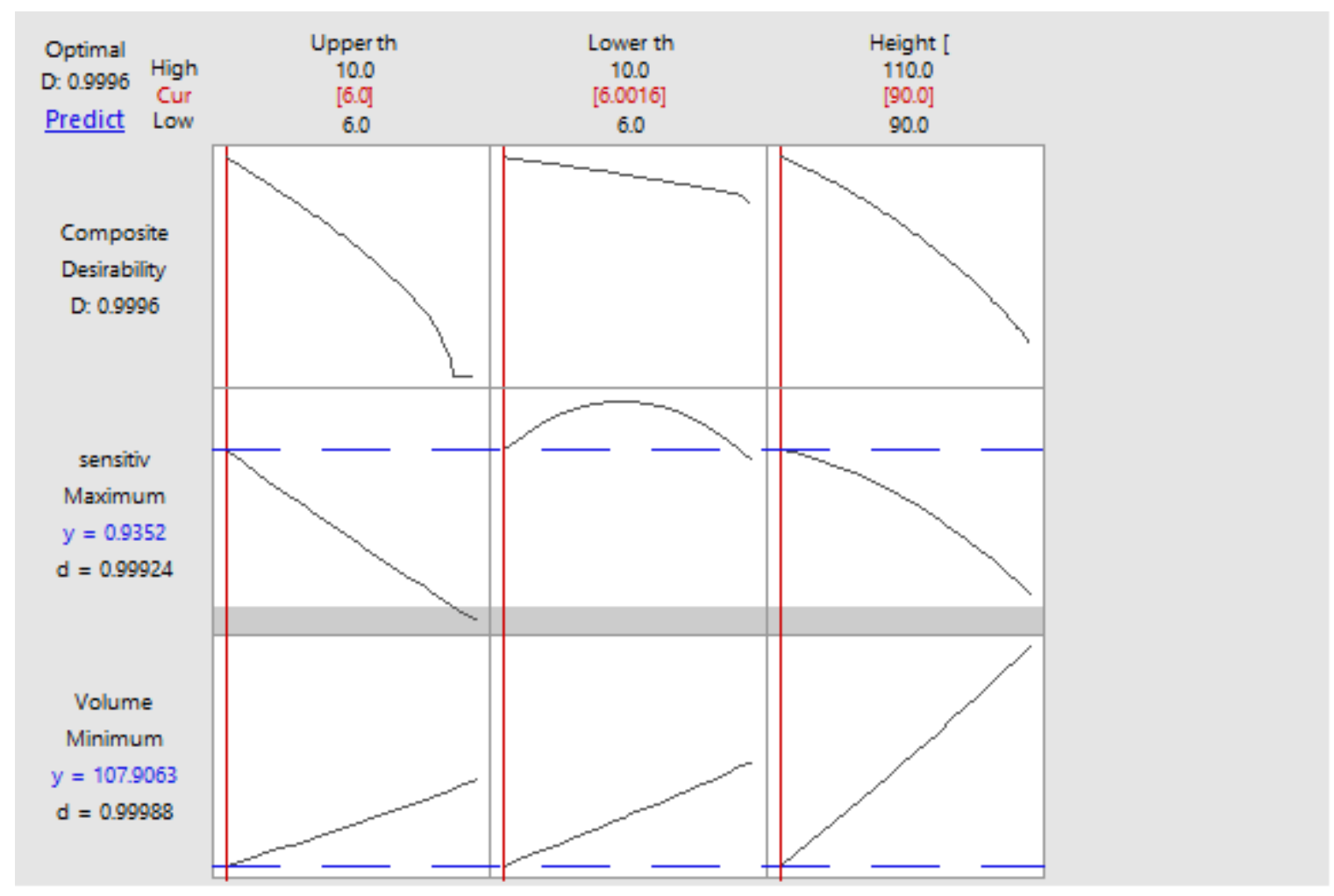

Fig.10: Optimization Curves using Desirability Function.

Table 5: Optimal Point Values Desirability Function

\begin{tabular}{|c|c|}
\hline Parameter & Values \\
\hline Upper Thickness & 6 \\
\hline Lower thickness & 6 \\
\hline Height & 90 \\
\hline
\end{tabular}

\section{CONCLUSION}

The aim of research work is to fine optimum gap of force transducer to get better response. The conclusion based on multiobjective optimization using Response Surface Methodology is summarized as follows;

1) The overall sensitivity increased from 0.11452 to $0.96475 \mu$ strain and volume decreased from 161.8 to $107.9 \mathrm{~mm}^{3}$

2) The analysis of Variance resulted that the thickness has major effect on sensitivity and volume. 


\section{REFERENCES}

1. Hernandez W., (2006) Improving the Response of a Load Cell by Using Optimal Filtering, Sensors, 6, 697-711.

2. Zolekar V.H. and Wankhade L. N. (2013) Finite Element Analysis and Optimization of I.C. Engine Piston Using RADIOSS and OptiStruct, Altair Technology Conference,1-8.

3. Myers, W.R. and Montgomery, D.C. (2003) Response surface methodology, Encycl Biopharm Stat, 1, 858-869.

4. Alimirzaloo V., Sadeghi, M. and Biglari, F. (2012) Optimization of the forging of aerofoil blade using the finite element method and fuzzy-pareto based genetic algorithm, Journal of mechanical science and technology, 26, 6, 1801-1810.

5. Aue-U-Lan, Y., Ngaile, G. and Altan, T. (2004) Optimizing tube hydroforming using process simulation and experimental verification, Journal of Materials Processing Technology, 146, 1, 137-143.

6. Candioti, L.V., De Zan, M.M., Camara, M.S. and Goicoechea, H.C. (2014) Experimental design and multiple response optimization Using the desirability function in analytical methods development, Talanta, 124, 123-138.

7. Vaibhav Varane, Vasudev Shinde, Vijay Kamble (2016) Effect of geometrical parameters on sensitivity and volume of rectangular beam force transducer. Journal of Recent Trends in Mechanics Volume 1 Issue 1 Page 1-14

8. Vaibhav Varane, Vasudev Shinde, Vijay Kamble (2016) Parametric optimization of Pancake Type Load Cell Using Response Surface Methodology E-ISSN 2277-4106, P-ISSN 2347-5161.

9. Thakkar K.H., Prajapati V.M. and Patel B.D., (2013) Performance Evaluation of Strain Gauge Based Load Cell to Improve Weighing Accuracy, International Journal of Latest Trends in Engineering and Technology, 2, 1, 103-107.

10. Kamble V.A. and Gore P.N., (2012) Use of FEM and Photo Elasticity for Shape Optimization of 'S' Type Load Cell, Indian Journal of Science and Technology, 5, 3, 2384-2389.

11. R. Kumar, S.Rab, B.D. Pant S. Maji (2018) FEA-Based Design Studies for Development of Diaphragm Force Transducers. Journal of Metrology Society of India.

12. Harish Kumar, Chitra Sharma and Anil Kumar(2011) Design and development of precision force transducer. 